International Journal of Physical Sciences and Engineering
Available online at http://sciencescholar.us/journal/index.php/ijpse
Vol. 2 No. 3, December 2018, pages: $62 \sim 69$
e-ISSN : 2550-6943, p-ISSN : 2550-6951
https://doi.org/10.29332/ijpse.v2n3.218

\title{
Demand in Abdon Calderon Parish for Possible Installation of Photovoltaic Systems
}

\author{
Katherine Lisbeth Carreno Suarez a, Andrade Garcia Jean Carlos b, Luis Adrian Saltos Cuenca c, \\ Jorge Alexander Gonzalez Zambranod d ${ }^{\mathrm{d}}$, Ángel Andrés Arteaga Ponce ${ }^{\mathrm{e}}$
}

Article history: Received 10 April 2018, Accepted: 30 August 2018, Published: 13 November 2018

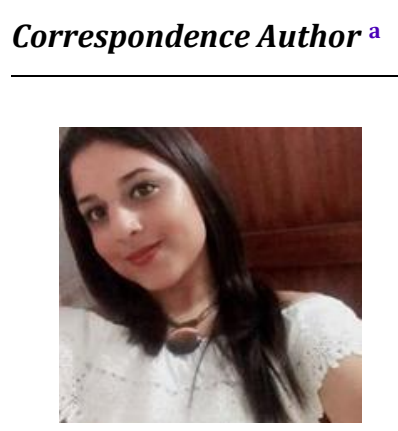

Keywords

Abdón Calderón;

Community development;

Photovoltaic system;

public luminaire;

Quality of lighting;

\begin{abstract}
Photovoltaic systems installed in Ecuador benefit from the geographical position of the country, since, being located on the equatorial line, solar radiation is constant throughout the year, varying in the rainy seasons. The objective of this work is to evaluate the possibility of installing public lighting systems using photovoltaic systems in the Abdón Calderón parish due to the difficulties that exist today, thereby helping not only to reduce the country's energy generation problems, but also to reduce the environmental impact and provide autonomy to the inhabitants of the parish. An observational research was carried out, in addition to interviewing the residents of the parish related to lighting in the streets, as a result, it was obtained that in the future investments can be made to introduce the technology, improving with it the quality of public lighting, the environmental and social impacts associated with it.
\end{abstract}

e-ISSN: 2550-6943, p-ISSN: 2550-6951 ${ }^{\circ}$ Copyright 2018. The Author. SS Journals Published by Universidad Técnica de Manabí. This is an open-access article under the CC BY-SA 4.0 license (https://creativecommons.org/licenses/by-sa/4.0/) All rights reserved.

\section{Contents}

Abstract

1. Introduction

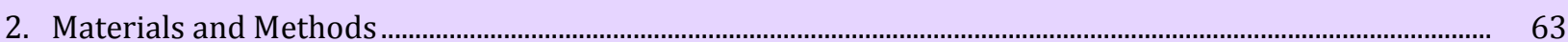

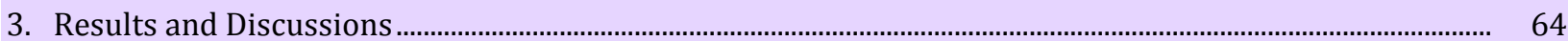

a Electrical Engineering, FCMFQ, Universidad Tecnica de Manabi, Portoviejo, Ecuador

b Electrical Engineering, FCMFQ, Universidad Tecnica de Manabi, Portoviejo, Ecuador

c Electrical Engineering, FCMFQ, Universidad Tecnica de Manabi, Portoviejo, Ecuador

d Electrical Engineering, FCMFQ, Universidad Tecnica de Manabi, Portoviejo, Ecuador

e Electrical Engineering, FCMFQ, Universidad Tecnica de Manabi, Portoviejo, Ecuador 
3.1 Photovoltaic Solar Energy in Ecuador ....

3.2 Public lighting with photovoltaic systems

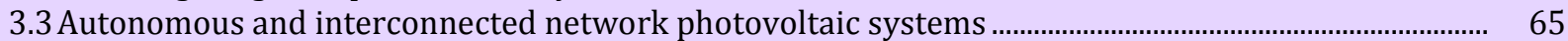

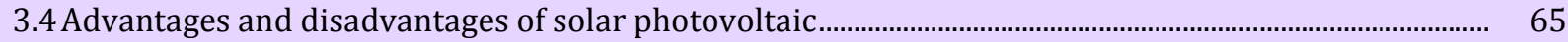

4. Conclusion

Acknowledgements..

References

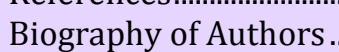

\section{Introduction}

Abdón Calderón is located between the coordinates 9882.100 and 9876.500 meters of north latitude and between the coordinates 585.300 and 567.600 meters of east longitude. There is an end-to-end difference in its $15.6 \mathrm{~km}$ latitude and an end-to-end difference in its length $17.7 \mathrm{~km}$. The most numerous communities are Miguelito, El Jobo, Quebrada de Guillén, La Balsa, Bijahual, El Hormiguero, Florestal, Maconta, Pimpiguasi.

Abdón Calderón Parish is immersed in the total population of the Portoviejo canton 280,029 with approximately 18,500 inhabitants, of which $50.60 \%$ of men predominate, out of the total of $49.40 \%$ of women (LinkedIn Corporation, 2014). The territorial structure of the rural parish comprises a space constituted by its parish head and the dispersed zone known as rural that includes the agricultural, livestock and forestry areas and the important ecological protection zone that constitutes the protective forests, wildlife sanctuaries, etc.

The parish head is a consolidated population structure that does not have its defined limits, which is made up of sectors in which low-density housing and housing trade predominate, characteristic of the rural areas of the Manabi coast. At present, due to climate changes and natural disasters caused by the increase of greenhouse gas emissions To the atmosphere, environmental awareness and the use of alternative energies are experiencing necessary and imminent growth. Among these energies, one of the most important is solar energy.

Solar energy is used directly from the sun's radiation, being currently one of the cleanest methods to produce energy. Currently, there is a strong increase in its use due to a series of advantages that it presents compared to conventional energy sources. Since ancient times, human beings have made use of the radiation that reaches the Earth through technologies that have been modified over time. Therefore, this energy is not a new concept. Today we know much more about the way we can use it, and a great example of this is in photovoltaic cells. In the whole world, solar energy is growing at a dizzying rate to adopt more small and local sources of power generation. Behind the wave of solar investment, last year is China which, by itself, added more than half of the world total of new production capacity. We cannot leave Latin America behind when, along with the Caribbean, they turn out to be one of the territories with the most radiation in the whole world. Mexico, Brazil, Chile, and Peru are the nations with the greatest capacity.

However, solar energy is moving at a very slow pace in Ecuador. The Ecuadorian solar market has developed until recently, especially in isolated installations of the rural electrification network. The first photovoltaic plant to be connected to the grid is located in the northern province of Imbabura, with a power of 998 KW (Plataforma América Látina, 2016). The photovoltaic systems installed in Ecuador benefit from the geographical position of the country, since, being this country in the middle of the world, solar radiation is constant throughout the year, varying in the rainy seasons. An installation of a photovoltaic system in Calderón for street lighting would not only help to reduce the country's energy generation problems, but also reduce the environmental impact and provide autonomy to the parishioners.

\section{Materials and Methods}

A randomized and simple prospective study was designed evaluating a sample of the population equivalent to 30 people over 18 years of age, excluding those under 18 years of age and of legal age since they have not lived in the study area a minimum of 2 years, the interview was used as information gathering instruments, analytical questions were asked to create an idea about the topics that were investigated,

Suarez, K. L. C., Carlos, A. G. J., Cuenca, L. A. S., Zambranod, J. A. G., \& Ponce, Ángel A. A. (2018). Demand in abdon calderon parish for possible installation of photovoltaic systems. International Journal of Physical Sciences and Engineering, 2(3), 62-69. https://doi.org/10.29332/ijpse.v2n3.218 
information that served to verify the existing problems. The survey was applied as a fundamental element in the investigation. The procedures applied allowed to obtain information or opinions from different sources based on the social circle, a way of life and socioeconomic position.

\section{Results and Discussions}

\subsection{Photovoltaic Solar Energy in Ecuador}

Ecuador is located in a privileged location in terms of solar radiation, because the equatorial line that divides the planet into two hemispheres passes through it, being almost perpendicular the radiation it receives. In addition, this does not change during the year and there is a constant angle of incidence, characteristics that give photovoltaic solar energy a great potential for use. There are different ways of using solar energy, the most obvious being the heating of water, food and the provision of energy that produces comfortable temperatures for living beings. It can also be used to generate electricity, through the use of photovoltaic solar panels. Currently, these are the most common and are easily found in the market at affordable prices

Although it is most efficient to locate the panels perpendicular to the sun's radiation, it is recommended to install them at an angle of $5^{\circ}$ to $15^{\circ}$ so that the water slips or any object that may fall. Having shade in a small area of a panel can reduce considerably the electrical energy production of the whole system, so it is advisable to verify that they are clear. Currently, the efficiency of a commercial solar panel is between $15 \%$ and $20 \%$, but it is expected to improve with technological development, generating more electricity. The current trend in the world is to opt for clean energy, so the installation of a photovoltaic system is a viable alternative for households, as long as their use is massified and their costs are reduced (Rodríguez \& Arroyo, 2016).

\subsection{Public lighting with photovoltaic systems}

Many cities or municipalities, as well as companies and individuals, are changing traditional urban lighting by solar luminaires for street lighting, thereby improving the environment and saving in a very important way the costs of lighting in urban areas, streets, avenues, highways, parking lots, sports fields, schools, roads, rural roads, parks and even residences.

A solar luminaire is a lighting device composed of an LED lamp, a photovoltaic solar panel, and a rechargeable battery. The solar luminaires for street lighting can have the lamp, solar panel and battery integrated into a single unit (.esco-tel, sf). Solar lights are recharged during the day. Automatics turn on at nightfall and remain lit at night, depending on the amount of sunlight they receive during the day. Some solar lights do not provide as much light as a networked lighting system, but they are easy to install and maintain and offer a cheaper alternative to wired lamps.

Solar street lighting is independent of the electricity network, which results in a reduction in operating costs. This means that they are wireless lights that are not connected to your electricity supplier. Solar luminaires require less maintenance than conventional street luminaires and have a lower chance of overheating. Since solar systems do not have external cables, the risk of accidents is minimized. In Abdon parish, there are 4589 sodium-mercury lamps, which are divided into 840 or 400 watts, 2350 of 250 watts, 1001 of 150 watts, 498 of 100 watts. These luminaries pollute the environment and one solution is the installation of an electric power generation system based on photovoltaic panels for street lighting.

\subsection{Autonomous and interconnected network photovoltaic systems}

Photovoltaic solar energy is obtained through photovoltaic solar panels exposed to Sun. This energy is worldwide the most widespread for electrification in remote areas where the public network has not arrived. Photovoltaic solar energy, in an economic approach, is the most viable for the generation of electricity in remote areas (Gámez, 2008), such as those that exist in Peru and Ecuador. 
These can be of two types: a) systems not connected to the network, which can have systems of accumulation of energy (batteries) or can have a simpler configuration, without batteries (autonomous) and b) systems connected to the network (Saltos et al., 2017). The interconnected photovoltaic (SF) systems are integrated by a photovoltaic array (set of solar modules) and an inverter, which is an electronic device that converts low voltage to high voltage. These do not have energy accumulation devices since the energy produced during the hours of insolation is channeled to the electric network; and during low or no heat hours, the consumption load comes from the network (Shared, 2016).

Autonomous Photovoltaic Systems (SFA) is probably one of the most widely used modern renewable energy systems for autonomous rural electrification worldwide, given that more than 500,000 rural households have these electrification systems, all over the world. Among the most relevant advantages of the OSS, it is found that, for their operation, they only depend on solar radiation as an energy resource, they do not require the supply of fuel (necessary in the generators or hybrids), which represents a problem for the electrification in rural communities (Ciaddy Gina Rodríguez-Borges, 2011).

\subsection{Advantages and disadvantages of solar photovoltaic}

The solar energy has several advantages, among which the following can be highlighted: It does not consume fuel, it obtains its energy from the Sun, which means that, economically, in the long term these systems are more viable and stable; the systems that today arrive at short times amortization (3-6 years) are the thermal systems of low temperatures; environmental impact practically nil; it is an inexhaustible resource; the generation of thermal energy without a process combustion, from the environmental point of view, is a procedure very favorable because it is clean and does not produce pollution; the photovoltaic systems do not produce any sound annoying when they operate because they do not have mechanical parts and movements so they do not cause any type of noise pollution; the systems have a long lifespan (more than 20 years); the maintenance of photovoltaic systems is simple and has very low costs; The installation of individual photovoltaic systems is simple, fast and only requires tools and equipment measuring basic.

\section{Like all sources of energy, solar has its disadvantages as well:}

The amounts of power and energy that can be obtained from a photovoltaic system are limited by the generation and storage capacity of the installed equipment, especially the modules and the battery respectively, and by the availability of the solar resource; budget constraints in terms of the capacity that can be installed; photovoltaic systems do not produce smoke; however, during the charging process the batteries in the isolated systems release the environment hydrogen into moderate quantities; the spillage of the sulfuric acid solution from the batteries represents a danger to the skin of people and to the soil; The availability of energy is variable and depends on the climatic conditions.

The Abdón Calderón Parish does not have photovoltaic luminaries, because it depends on various factors, such as a geographical position where it is going to be installed and the economy of decentralized autonomous government $(\mathrm{GAD})$ of the parish since the installation is more expensive compared to conventional public lighting.

In recent years, due to the great reception of foreigners that the parish has had, security has decreased, which is why if photovoltaic luminaires are implemented, the risk of accidents is minimized since they are not wired, but they can be easily stolen. The risk of theft is relatively greater because it has a higher monetary value compared to conventional lighting, so there should be more vigilance in the areas where they are installed to avoid this type of event. One of the dangers that present the parish is the power line, since, since the earthquake of April 16, 2016, most of the cables were hanging, and the electricity company to date has been able to fix this problem. Figure 1 shows the state of the cables in the center of the parish, where a lot of lighting is used, and now more with the implementation of the new market,

Suarez, K. L. C., Carlos, A. G. J., Cuenca, L. A. S., Zambranod, J. A. G., \& Ponce, Ángel A. A. (2018). Demand in abdon calderon parish for possible installation of photovoltaic systems. International Journal of Physical Sciences and Engineering, 2(3), 62-69. https://doi.org/10.29332/ijpse.v2n3.218 


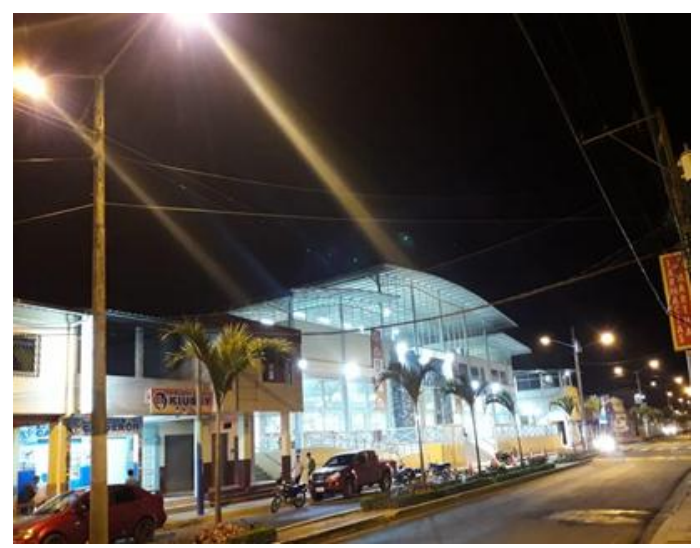

Figure 1. Public lighting in the Abdón Calderón parish

A survey was applied in the community to know the knowledge that its inhabitants of the parish had regarding the use of photovoltaic luminaries, one of the first results obtained highlights that $57 \%$ of the people surveyed do not know the technology, including its benefits before climate change and the use of it.

In figure 2 , it is observed that $71 \%$ of the population do not know what a solar panel is, which indicates that there is a complete ignorance of the methods of obtaining renewable energy from the surveyed population, only $29 \%$ know that it is a solar panel, demonstrating the lack of knowledge in when to use clean technologies to produce energy.

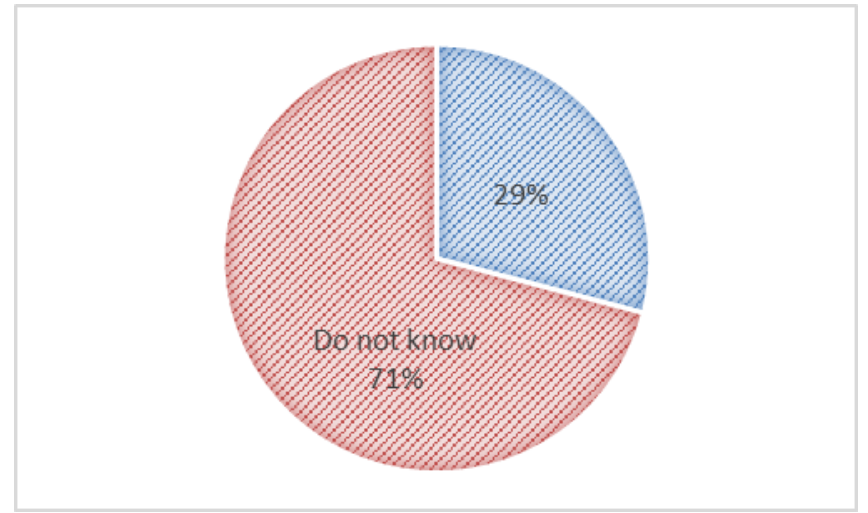

Figure 2. Percentage of the population that does not know the technology

Despite the lack of knowledge of renewable sources of energy, people show a desire to be trained in the subject with 90\% acceptance, as shown in Figure 3, people want to learn something new and it is a viable data for the execution of the project, while $10 \%$ are not interested in receiving information on the subject exposed. 


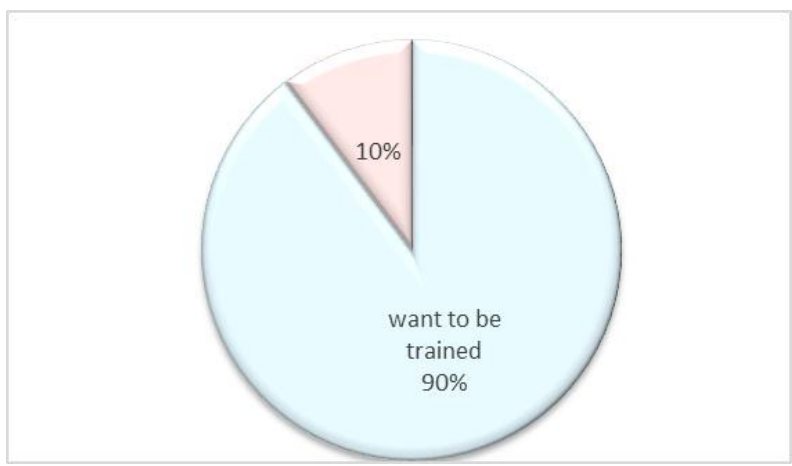

Figure 3. People who want to learn something new

It was confirmed that the percentage that only $50 \%$ of the population wants to be benefited with public lighting systems that use photovoltaic systems because of their social impact and the efficiency they have in relation to other luminaries.

\section{Conclusion}

1. An investigation was carried out related to the use of the photovoltaic effect and showed the current state of the penetration of photovoltaic solar energy in different developed countries and Latin America.

2. Knowing that the generation of photovoltaic energy brings advantages, it is considered that all countries should implement this new system because thanks to this, nature is contributed and this is also very profitable in relation to other sources.

3. It is evaluated as Ecuador to be located in the equatorial line is a privileged country for the use of this technology, in areas where it is generated with fossil fuels or in places where energy arrives with poor quality and may suggest that the parish "Abdón Calderón "may in the future be able to invest in this technology, improving with it the locality of energy and the environmental and social impacts associated with it.

4. The research allowed deepening the knowledge of photovoltaic technology and its use. Because solar street lighting is independent of the electricity grid, there is a decrease in operating costs since they require less maintenance and have a lower chance of overheating

\section{Acknowledgments}

Special recognition is given to María Rodríguez Gámez Ph.D. Academic professor and the subject of scientific research that has allowed us with his teachings to carry out this research

Suarez, K. L. C., Carlos, A. G. J., Cuenca, L. A. S., Zambranod, J. A. G., \& Ponce, Ángel A. A. (2018). Demand in abdon calderon parish for possible installation of photovoltaic systems. International Journal of Physical Sciences and Engineering, 2(3), 62-69. https://doi.org/10.29332/ijpse.v2n3.218 


\section{References}

Esco-tel. (sf) Recovered on 2018, from http://www.esco-tel.com/

Gámez, A. \&. (2008). Impact on the generation of electricity with unconventional sources of energy in the Mexican electric power system. Energy Engineering, XXIX(3), 18-25.

Renova Energy. (sf) Autonomous Photovoltaic Solar Energy.

Arauz, W. M. S., Gámez, M. R., Pérez, A. V., Castillo, G. A. L., \& Alava, L. A. C. (2017). The Future of Micro-Grids in Ecuador. International Journal of Physical Sciences and Engineering (IJPSE), 1(3), 1-8.

Ciaddy Gina Rodríguez-Borges, AS-S. (April 2011). Dimensioning by simulation of photovoltaic solar energy systems applied to rural electrification. Scielo, 14(1). Retrieved from

LinkedIn Corporation. (November 26, 2014). Research work: Pardo Abdón Calderón del Cantón Portoviejo. (UT Manabí, Producer)

Rodríguez, D., \& Arroyo, D. (July 8, 2016). Photovoltaic solar energy in Ecuador. Daily The Telegraph.

Shared, F. d. (August 03, 2016). Autonomous Photovoltaic Systems and Interconnected to the Network. (Gob.mx, Producer)

Solar platform América Latina. (October 26, 2016). Solar photovoltaic Ecuador. Sopelia. 


\section{Biography of Authors}

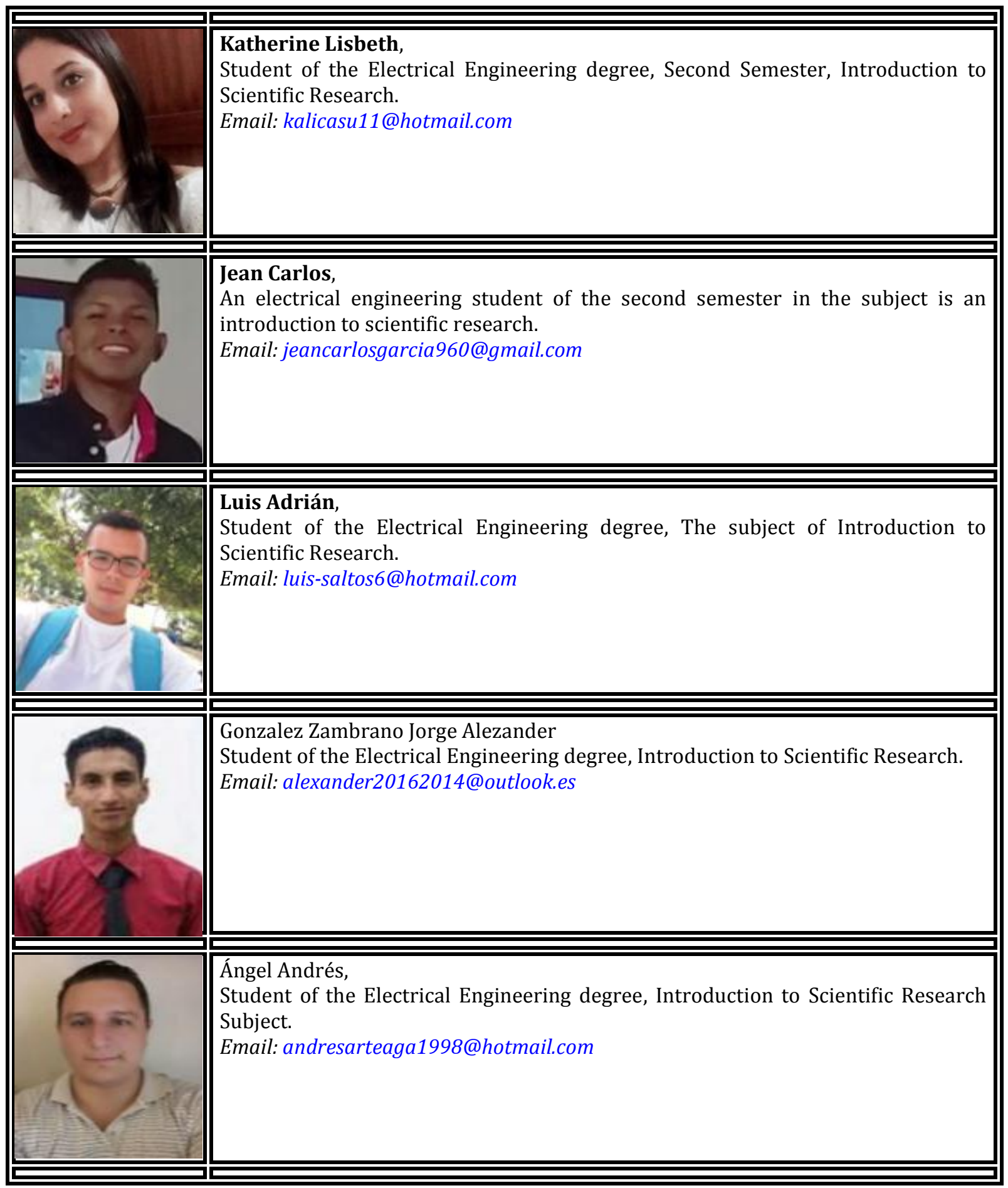

Suarez, K. L. C., Carlos, A. G. J., Cuenca, L. A. S., Zambranod, J. A. G., \& Ponce, Ángel A. A. (2018). Demand in abdon calderon parish for possible installation of photovoltaic systems. International Journal of Physical Sciences and Engineering, 2(3), 62-69. https://doi.org/10.29332/ijpse.v2n3.218 